\title{
Determinants of Dental Health Problems Among Adult Patients at Dental Clinic, Debre Berhan Comprehensive Specialized Hospital, Ethiopia: Unmatched Case-Control Study
}

\author{
Behailu Tariku Derseh (iD) \\ Kassahun Mekonnen ${ }^{2}$ \\ Tibebu Kibret ${ }^{3}$ \\ Assalif Beyene (iD ${ }^{4}$ \\ Abebe Mihretie (iD) ${ }^{4}$ \\ 'Department of Public Health, Asrat \\ Woldeyes Health Sciences Campus, \\ Debre Berhan University, Debre Berhan, \\ Ethiopia; ${ }^{2}$ Felege Hiwot Comprehensive \\ Specialized Hospital, Bahirdar, Amhara, \\ Ethiopia; ${ }^{3}$ Department of Medicine, Asrat \\ Woldeyes Health Sciences Campus, \\ Debre Berhan University, Debre Berhan, \\ Ethiopia; ${ }^{4}$ Department of Midwifery, \\ Asrat Woldeyes Health Sciences Campus, \\ Debre Berhan University, Debre Berhan, \\ Ethiopia
}

Purpose: This study was aimed to assess the determinants of dental health problems among adult patients at the dental clinic of Debre Berhan Comprehensive Specialized Hospital, Ethiopia.

Methods: A case-control study was conducted to recruit a total of 267 adults (cases $=134$, and controls $=133$ ) who received oral health screening service in Debre Berhan Comprehensive Specialized Hospital, 2018. Data were collected by physical examination and pretested semi-structured questionnaire from March 1 to 31, 2018. Collected data were entered in EpiData 3.1 and analyzed by using SPSS version 20. Bivariable and multivariable logistic regressions were done via the forward stepwise method. Variables were declared statistically significant when p-value $<0.05$.

Results: Of the total study participants, 75 (55\%) of cases and $62(46.6 \%)$ of controls were males. The mean age $( \pm \mathrm{SD})$ of cases was $36.2( \pm 14.2)$ years and that of controls was $31.4( \pm 10.3)$ years. The classification table revealed that the sensitivity of cases was $70.7 \%$, and the specificity of controls was $74.8 \%$. This study showed that $28(20.89 \%)$ of cases and $6(4.5 \%)$ of controls had confirmed gastritis $(\mathrm{P}<0.05)$. Regarding dental health information, $78(58.2 \%)$ of cases and 123 $(92.5 \%)$ of controls perceived that they had received dental health information from different sources. Access to dental health information and tooth brushing practice reduced dental health problems (adjusted odds ratio $(\mathrm{AOR})=0.28 ; 95 \% \mathrm{CI}$ : $0.12,0.64$; and $\mathrm{AOR}=0.24 ; 95 \% \mathrm{CI}$ : 0.13 , $0.45)$, respectively, whereas study participants who had gastritis were at increased risk of developing dental health problems ( $\mathrm{AOR}=3.12$; 95\% CI: 1.14, 8.57).

Interpretation: Study participants who had adequate information on dental health had a reduced risk of developing dental health problems by $72 \%$ and participants who practiced tooth brushing were at reduced risk of developing dental health problems by $76 \%$. However, individuals who had gastritis were 3 times more likely to develop dental health problems compared with their counterparts.

Conclusion: In summary, health information, tooth brushing practice, and gastritis infection were the determinants of dental health problems. Thus, health information dissemination on dental health particularly on how to prevent and control dental health problems is very critical. Moreover, strategies to combat gastritis integrated with life course principles should be strengthened to improve dental health.

Keywords: dental health, Ethiopia, gastritis, health information, tooth brushing

\section{Introduction}

The World Health Organization (WHO) defines oral health as 
a state of being free from mouth and facial pain, oral and throat cancer, oral infection and sores, periodontal disease, tooth decay, tooth loss, and other diseases and disorders that limit an individual's capacity in biting, chewing, smiling, speaking, psychosocial wellbeing, ability to communicate and self-esteem.

A healthy and well-functioning dentition is important during all stages of life since it supports essential human functions. ${ }^{1}$ There are many forms of oral disease with different signs and symptoms, which are either preventable or treatable in their early stages: tooth decay and cavities, gum diseases, oral cancers, noma, oral manifestations of HIV and AIDS, orofacial trauma from accidents, and violence, cleft lip and palate that affects their ability to speak, to eat and to take part in all the routines of normal life. ${ }^{2}$ Poor hygiene, genetic factors, stress, knowledge, attitude, systemic diseases such as diabetes, cardiovascular diseases, adverse pregnancy outcomes, and respiratory diseases are some of the important risk factors for oral disease. ${ }^{1,3,4}$ Other important factors could be age, sex, income, educational status, gastric infection, diabetes mellitus, oral health literacy, and tooth cleaning. $^{5-10}$

In 2020, the promotion of self-care is one of WHO's goals to improve oral health of the populations. These include tooth brushing more than once a day, lesser consumption of sugar-containing snacks, and regular use of fluoride-containing toothpaste. Studies have shown that there is an association between increased knowledge regarding oral hygiene and better oral health. ${ }^{11}$ Conversely, the majority of the people are unaware of the relationship between oral hygiene and systemic diseases. Many diseases show their first appearance through oral signs and symptoms and they remain unchanged or untreated because of the lack of knowledge, attitude, and practice on oral hygiene. ${ }^{12}$ For instance, proper tooth brushing practice prevents the development of dental health problems and has an effect on the quality of life and general health of people. ${ }^{13}$ Moreover, dental checkups twice a year, creating awareness to the public, prevent systemic diseases are helpful for the prevention and control of dental health problems. ${ }^{14,15}$

According to the global burden of oral health conditions, the number of people with untreated oral conditions rose from 2.5 billion in 1990 to 3.5 billion in 2015, indicating oral health problems are highly prevalent in the globe, and posing a very serious public health challenge to policymakers. ${ }^{16}$ Even though fluorides in the form of toothpaste, and/or fluoridated water, mouth rinses, and clinical topical fluorides have benefits, populations in many developing countries do not have access to fluorides for practical or economic reasons. ${ }^{3}$ This in turn affects individuals to talk, eat and socialize without experiencing active disease, discomfort, or embarrassment. ${ }^{17}$ Even if a dental health problem is a major public health concern, the knowledge, attitude, and practice towards the prevention measure is yet not at a level of preventing the burden. For example, knowledge of the dental problems in Kuching was estimated as $56.5 \%,{ }^{18}$ in Kenya $43 \%$ of the participants did not know any causes of dental diseases, and $50 \%$ did not know any preventive measures for dental diseases. ${ }^{19}$ Similarly, a study done in Addis Ababa, Ethiopia, showed $28.8 \%$ of the respondents have knowledge of the correct techniques of tooth brushing. ${ }^{13}$ In Nigeria, $72.5 \%$ and $26 \%$ of the teachers had a negative attitude and poor practice of oral health, respectively. ${ }^{17}$ Therefore, this study was aimed at determining the factors associated with dental health problems among adult patients in Debre Berhan Comprehensive Specialized Hospital. Since identifying determinants is very crucial to generate evidence that help to prevent, control, and reduce dental health problems. Moreover, this study is expected to fill the gaps in the scarcity of evidence on this particular area.

\section{Methodology}

\section{Study Area and Period}

The study was conducted at Debre Berhan Comprehensive Specialized Hospital (DBCSH), located at about $130 \mathrm{~km}$ away from Addis Ababa, in Debre Berhan Town, North Shoa Zone, Amhara, Ethiopia. The average annual temperature of the town during day and nighttime is estimated as $20.7^{\circ} \mathrm{C}$ and $8.2^{\circ} \mathrm{C}$, respectively. The hospital was established in 1928 and serves for about 1.2 million people in its catchment area. This hospital serves for an average of 400-450 patients daily through both direct and referral systems. There are a total of 152 beds for inpatient service and provides preventive, curative, and rehabilitative services. The study was conducted from March 1 to 31, $2018 .^{20}$

\section{Study Design}

Institution-based, unmatched case-control study was conducted to assess the determinants of dental health 
problems among adult patients at DBRH dental clinic from March 1 to 31, 2018.

\section{Study Participants Selection}

Patients who came to DBCSH dental clinic for diagnosis and treatment in the month of March 2018 were the study population for cases and those patients at DBCSH other than dental clinic and free from dental health problems were the study population for the controls. Selection of cases and controls were performed by intern medical doctors and senior dentists working in the dental clinic. All patients whose age is greater than 18 , had dental health problems, and came to dental clinic, during data collection time were included in the study until the number of cases reached. On the other hand, controls were selected from DBCSH who were free from dental health problems as confirmed by the dentist. Those patients who are severely ill during the data collection time were excluded from the study.

\section{Examination of Dental and Oral Health Problems}

A dental doctor at a dental clinic outpatient department (OPD) examines dental and oral health problems by closely inspecting patients' teeth, mouth, throat, tongue, cheeks, jaws, and neck. If they get tooth decay, inflammation of the gums, infection of jaws and bones, cracked or broken teeth, and sensitive teeth based on the World Health Organization (WHO) protocol. ${ }^{21}$ After the clinical dental examination, data collectors administered the exit questionnaire. These patients were considered as cases. ${ }^{2}$

\section{Sample Size Determination and Technique}

The sample size of this study was determined by using the formula indicated in equation (1), considering the following assumptions. Two-sided confidence level (95\%), power $(80 \%)$, the ratio of controls to cases $(1: 1)$, percentage of controls exposed $(77.6 \%)$, Odds Ratio $(\mathrm{OR}=0.42)$ for teeth brushing practice, and percentage of cases with exposure $(59.3 \%){ }^{5}$ Thus, 111 cases and 111 controls were taken to make the total sample size 222. Finally, adding $20 \%$ of the non-response rate, the total study participants calculated was 267 . A consecutive sampling technique was used to select cases until sample size was reached, whereas a convenient sampling technique was used to select the controls from the same hospital who visited the facility for other than a dental problems.

$$
n=\left(\frac{r+1}{r}\right) \frac{(\bar{p})(1-\bar{p})\left(Z_{\beta}+\mathrm{Z}_{\alpha / 2}\right)^{2}}{\left(\mathrm{p}_{1}-p_{2}\right)^{2}}
$$

\section{Data Collection Tool, Procedure, and Quality Control}

To measure the dependent and independent variables, two types of approaches were used; questionnaire and dental examination. Dental examination was performed by examining the patient to identify the following dental health problems; sores, or tender areas in the mouth that will not heal after a week or 2, bleeding or swollen gums after brushing or flossing, chronic bad breath, sudden sensitivity to hot and cold temperatures or beverages, pain or toothache, loose tooth, receding gums, and pain with chewing or biting. ${ }^{22}$ To measure other determinants of dental health problems, a semi-structured interviewer-administered questionnaire was designed for this particular study. The tool was composed of closed-ended and open-ended questions consisting of five sections. These were 1) the sociodemographic section (7 items), 2) knowledge assessing questions (19 items), 3) attitude assessing questions (5 items), 4) dental health practice assessing questions (16 items), and 5) questions assessing the behavioural factors (10 items). The questionnaire was prepared first in the English language then translated into the local language (Amharic) then back to the English language to check the consistency (Supplementary Materials). The content validity of the translated questionnaire was evaluated by public health experts, a dental doctor, and medical doctors who are fluent in the local language. Based on their endorsements, modifications to the survey tool were made. Generally, the tool tried to assess study participants' sociodemographic background, knowledge, attitude, the practice of patients for dental health, and other risk factors including comorbidities. Data collectors and supervisors were trained about the objectives of the study, and how to collect data from clients visiting the dental clinic. Before actual data collection, a pretest was done on $5 \%$ of the sample size, and these data were excluded from the final analysis. The reliability analysis was done by using Cronbach's alpha test (Cronbach's alpha for knowledge = 0.45 and Cronbach's alpha for attitude $=0.35$ ).

\section{Operational Definition}

Dentists: They are the principal providers of oral disease treatment and prevention. Their role is changing in response to emerging risk factors, evolving disease 
burdens, demographic changes, and broader health system and socioeconomic pressures.

Sodium-fluoride: It is part of the WHO model list of essential medicine, and access to fluorides has been recognized as a part of the basic human right to health.

Poor dental knowledge: Study participants who scored less than the median value of overall knowledge score calculated from the 19-item questionnaire.

Good dental knowledge: Study participants who scored above the median value of overall knowledge score calculated from the 19-item questionnaire.

Unfavourable attitude: Study respondents who scored less than the median value of overall attitude score calculated from the 5-item questionnaire.

Favourable: Study participants who scored above the median value of overall attitude score calculated from the 5-item questionnaire.

\section{Data Management and Analysis}

The collected data were entered into Epi Data 3.1 software and checked for inconsistencies before analysis. Data exploration was used to identify and manage missing values, inconsistencies, and outliers. Then, data were coded to produce categorical variables from metric variables (eg, age, and income). Data analysis was performed by SPSS software version 20 . Normality was checked by using Shapiro Wilk test $\left(X^{2}=0.96, d f=266\right.$, p-value $<0.05$ for knowledge, and $X^{2}=0.88, d f=266$, p-value $<0.05$ for attitude) and visual inspection of histogram and box and whisker plots. Descriptive statistics including mean, median, frequency, and percentage on dental health problem determinants were calculated and presented in the form of tables. The dependent variable is coded as $0 \mathrm{~s}$ and $1 \mathrm{~s}$ $($ Cases $=1$ and Controls $=0)$. Logit regression or logit model is used to estimate the probability of an event occurring having been given our dataset collected for this study. Logistic regression works with binary data, where either the event happens (cases $=1$ ) or the event does not happen (controls $=0$ ). In this model, the measure of association between dependent and explanatory variables is estimated by crude odds ratio (COR) and adjusted OR. The cut-off $\mathrm{p}$-value for COR is 0.25 , whereas for AOR the cut-off value is (p-value $<0.05$ ). Bivariable logistic regression and multivariable logistic regression analysis were done, and variables that were significantly associated in bivariable logistic regression at $\mathrm{p} \leq 0.25$ were further taken to multivariable logistic regression and then the significant association of each variable was declared at $\mathrm{p}$-value $<0.05$.
A forward stepwise-likelihood ratio method of logistic regression used was significant at Omnibus Test of Model Coefficients $\left(X^{2}=75.42, d f=1\right.$, and P-value $<0.001)$, Model summary $(-2$ Log-likelihood $=291.91$, Nagelkerke R square $=0.33)$, and Hosmer and Lemeshow test $\left(X^{2}=1.34, d f=4, \mathrm{p}\right.$-value $\left.=0.84\right)$. The sensitivity and specificity of cases and controls are provided by the classification table (sensitivity of cases $=$ $70.7 \%$ and specificity of controls $=74.8 \%$, and the overall percentage of $72.8 \%$ ).

\section{Results}

\section{Socio-Demographic Characteristics}

This study revealed that a total of 267 participants (134 cases and 133 controls) have participated in the interview giving a response rate of $100 \%$. Of the total study participants, $75(55 \%)$ of cases and $62(46.6 \%)$ of controls were males. The mean age $( \pm \mathrm{SD})$ of cases was $36.2( \pm 14.2)$ years and that of controls was $31.4( \pm 10.3)$ years. The Chi-Square analysis revealed that variables' religion, occupation, educational status, and average monthly income of the participants had a linear association with dental health problems at $p$-value $<0.05$ (Table 1).

\section{Knowledge, Attitude, and Practice on Dental Health Problems}

This study showed that $37(27.6 \% ; 95 \%$ CI: $19.9 \%$, $35.3 \%)$ of cases and 60 (45\%; 95\% CI: $36.6 \%, 53.7 \%)$ of controls had good knowledge on the signs, symptoms, prevention, and control of dental health problems $\left(X^{2}=\right.$ $8.84, d f=1$, p-value $<0.05)$. Similarly, $22(16.5 \%$; $95 \%$ CI: $10.1 \%, 22.9 \%)$ of cases and $51(38.4 \% ; 95 \%$ CI: $29.9 \%, 46.7 \%$ ) of controls had favourable attitude towards the prevention, and control of dental health problems $\left(X^{2}=\right.$ $15.8, d f=1$, p-value $<0.001)$. Moreover, $46(34.3 \%$; $95 \%$ CI: $26.2 \%, 42.5)$ of cases and $107(80.4 \% ; 95 \%$ CI: $73.6 \%, 87.3)$ of controls had good practice of brushing their tooth (Table 2). The Chi-Square analysis showed that there was tooth brushing difference among cases and controls $\left(X^{2}=58.1, d f=1, \mathrm{p}\right.$-value $\left.<0.001\right)$. The details are presented in the next table (Table 2). Out of the total participants $86(64.2 \%)$ of cases and $69(51.8 \%)$ of controls mentioned taking sugar foods as the cause of tooth decays. In addition to these, $81(60.4 \%)$ of cases and $89(66.9 \%)$ of controls thought that dental problem affects their general health (Tables 2-4). 
Table I Socio-Demographic Characteristics of Study Participants, DBCSH Dental Clinic, 2018

\begin{tabular}{|c|c|c|c|c|c|c|c|}
\hline \multirow[t]{2}{*}{ Variables } & \multicolumn{2}{|c|}{ Cases $(n=134)$} & \multicolumn{2}{|c|}{ Controls $(n=133)$} & \multirow[t]{2}{*}{$x^{2}$-value } & \multirow[t]{2}{*}{$d f$} & \multirow[t]{2}{*}{ P-value } \\
\hline & Frequency & $\%$ & Frequency & $\%$ & & & \\
\hline \multicolumn{8}{|l|}{ Sex } \\
\hline Male & 75 & 55.9 & 62 & 46.6 & 2.34 & 1 & 0.126 \\
\hline Female & 59 & 44.1 & 71 & 53.4 & & & \\
\hline \multicolumn{8}{|l|}{ Religion } \\
\hline Orthodox & 114 & 85.1 & 97 & 72.9 & 7.96 & 2 & 0.019 \\
\hline Muslim & 17 & 12.7 & 24 & 18.0 & & & \\
\hline Protestant & 3 & 02.2 & 12 & 09.1 & & & \\
\hline \multicolumn{8}{|l|}{ Occupation } \\
\hline Student & 23 & 17.2 & 26 & 19.5 & 30.31 & 5 & $<0.001$ \\
\hline Gov't employee & 20 & 14.9 & 47 & 35.3 & & & \\
\hline Merchant & 23 & 17.2 & 29 & 21.8 & & & \\
\hline Farmer & 43 & 32.1 & 14 & 10.5 & & & \\
\hline Daily labourer & 15 & 11.1 & 14 & 10.5 & & & \\
\hline House wives & 10 & 07.5 & 3 & 02.3 & & & \\
\hline \multicolumn{8}{|l|}{ Educational status } \\
\hline No formal education & 53 & 39.6 & 22 & 16.5 & 13.49 & 1 & $<0.001$ \\
\hline Have formal education & 81 & 60.4 & 111 & 83.5 & & & \\
\hline \multicolumn{8}{|l|}{ Average income } \\
\hline$<1500$ ETB & 75 & 55.9 & 57 & 42.8 & 4.6 & 1 & 0.032 \\
\hline$\geq 1500 \mathrm{ETB}$ & 59 & 44.1 & 76 & 57.2 & & & \\
\hline
\end{tabular}

\section{Risk Factors Associated}

After checking the assumptions of logistic regression, the following variables were statistically significant at a p-value less than 0.25; age group, sex, educational status, income category, access to dental health information, having radio, television, good knowledge, tooth brushing, drinking alcohol, and having gastritis. Then, controlling the confounding effects of independent variables, the following variables were statistically significant in a multivariable analysis at a 5\% level of significance. These predictors were having access to health information on dental health $(\mathrm{AOR}=0.28$; $95 \%$ CI: $0.12,0.64)$, tooth brushing practice $(\mathrm{AOR}=0.24$; 95\% CI: $0.13,0.45$ ), and participants who had gastritis (AOR $=3.12$; 95\% CI: 1.14, 8.57) (Table 5).

\section{Discussion}

Out of eleven variables in bivariable logistic regression analysis, only three variables; dental health information, tooth brushing practice, and having disease gastritis were statistically significant contributing $33 \%$ of the variation in developing dental health problems $(-2$ Log-likelihood $=291.91$, Nagelkerke R square $=0.33$ ). This study explained that study participants who had adequate information on dental health had a reduced risk of developing dental health problems by $78 \%$ and participants who had a good practice of tooth brushing were at reduced risk of developing dental health by $76 \%$. However, individuals who had gastritis were 3 times more likely to develop dental health problems compared with their counterparts.

A primary focus on prevention of dental health problems implementation of population-level interventions that improve the knowledge, attitude, and practice towards oral health through the concept of life course approach is mandatory. This study showed that dental health information reduced the burden of contracting dental health problems. This result is similar to the study finding in Addis Aba, ${ }^{13}$ Debre Tabor, ${ }^{6}$ Ethiopia, and on update ${ }^{8}$ reviewed, in which dental health status was affected by the participant knowledge level. This may be due to that those individuals with better knowledge levels will have more desire to seek oral health care practice and hence prevent oral health problems. Moreover, the higher the health information about dental health problems, the chance of seeking health care especially dental check-ups will be increased. Additionally, they will also refrain from bad behaviours that can bring dental caries like drinking 
Table 2 Response of Study Participants on Knowledge Assessing Questions in DBCSH Dental Clinic, Ethiopia, March 2018

\begin{tabular}{|c|c|c|c|c|c|c|c|c|}
\hline \multirow[t]{2}{*}{ Variables } & \multirow[t]{2}{*}{ Options } & \multicolumn{2}{|c|}{ Cases } & \multicolumn{2}{|c|}{ Control } & \multirow{2}{*}{$\begin{array}{c}X^{2}- \\
\text { value }\end{array}$} & \multirow[t]{2}{*}{$d f$} & \multirow[t]{2}{*}{ P-value } \\
\hline & & Frequency & Percent & Frequency & Percent & & & \\
\hline \multirow[t]{4}{*}{ Causes of tooth decay } & Sugar foods & 86 & 64.2 & 69 & 51.8 & & & \\
\hline & Germs & 37 & 27.6 & 57 & 42.8 & & & \\
\hline & Hard foods & 1 & 0.7 & 6 & 4.5 & & & \\
\hline & I do not know & 10 & 7.4 & I & 0.7 & & & \\
\hline \multirow[t]{2}{*}{ Tooth decay prevented } & Yes & 121 & 90.3 & 130 & 97.0 & & & \\
\hline & No & 13 & 9.7 & 3 & 6.7 & & & \\
\hline \multirow[t]{3}{*}{ Ways of prevention } & Brushing after meal & 96 & 71.6 & 80 & 60.2 & & & \\
\hline & Regular dental check-up & 22 & 16.4 & 37 & 27.8 & & & \\
\hline & Avoid hard foods & 18 & 13.4 & 16 & 12.3 & & & \\
\hline \multirow[t]{4}{*}{ What causes black spot } & Chat & 102 & 76.1 & 117 & 87.9 & & & \\
\hline & Cigarette & 113 & 84.3 & 111 & 83.5 & & & \\
\hline & Tea & 11 & 8.2 & 10 & 7.5 & & & \\
\hline & Others & 6 & 4.4 & 1 & 0.7 & & & \\
\hline \multirow{2}{*}{$\begin{array}{l}\text { Yellowish or brown colour on } \\
\text { tooth }\end{array}$} & Unhealthy gum & 114 & 85.1 & 124 & 93.2 & & & \\
\hline & Healthy gum & 20 & 14.9 & 9 & 6.7 & & & \\
\hline \multirow{4}{*}{$\begin{array}{l}\text { What treatment would you } \\
\text { prefer }\end{array}$} & Filling & 23 & 17.2 & 40 & 30.0 & & & \\
\hline & Extraction & 109 & 81.3 & 91 & 68.4 & & & \\
\hline & Artificial & 0 & 0.00 & 1 & 0.7 & & & \\
\hline & I do not know & 2 & 1.5 & I & 0.7 & & & \\
\hline \multirow{3}{*}{$\begin{array}{l}\text { Fluorides can prevent tooth } \\
\text { decay }\end{array}$} & Agree & 42 & 31.3 & 70 & 52.6 & & & \\
\hline & Disagree & 91 & 67.9 & 63 & 47.3 & & & \\
\hline & Do not know & 1 & 0.7 & 0 & 0 & & & \\
\hline \multirow[t]{3}{*}{ Mouth wash prevent decay } & Agree & 82 & 61.2 & 114 & 85.7 & & & \\
\hline & Disagree & 47 & 35.1 & 18 & 13.5 & & & \\
\hline & Do not know & 5 & 3.7 & I & 0.7 & & & \\
\hline \multirow[t]{3}{*}{ Healthy tooth looks } & White and shiny & 64 & 47.8 & 68 & 51.1 & & & \\
\hline & Strong and caries free & 70 & 52.2 & 63 & 47.3 & & & \\
\hline & Do not know & 0 & 0 & 2 & 1.5 & & & \\
\hline \multirow[t]{2}{*}{ Sweet foods cause caries } & Yes & 123 & 91.8 & 126 & 94.7 & & & \\
\hline & No & 11 & 8.2 & 7 & 5.3 & & & \\
\hline \multirow[t]{2}{*}{ Cold drinks causes caries } & Yes & 32 & 23.9 & 55 & 41.4 & & & \\
\hline & No & 102 & 76.1 & 78 & 58.6 & & & \\
\hline \multirow[t]{2}{*}{ Is dental check-up important } & Yes & 93 & 69.4 & 108 & 81.2 & & & \\
\hline & No & 41 & 30.6 & 25 & 18.8 & & & \\
\hline \multirow[t]{2}{*}{ Knowledge status } & Good & 37 & 27.6 & 60 & 45 & 8.8 & I & 0.003 \\
\hline & Poor & 97 & 72.4 & 73 & 55 & & & \\
\hline
\end{tabular}

alcohol and chewing khat $^{6}$ and healthy behaviours like tooth brushing, flossing, and avoiding sweet food practice. ${ }^{6,8,23,24}$

Another important factor associated with dental health problems is tooth brushing. This study showed that tooth brushing practice reduced dental health problems by $76 \%$ compared with individuals who did not brush their teeth. This finding is similar to the study finding of Bahir Dar Ethiopia, Uganda, and Palestine, and this may be due to the fact that tooth brushing practice may remove those food remnants and bacteria that can damage the tooth. ${ }^{7,25,26}$ Similarly, a study from the University of 
Table 3 Attitude of Study Participants Towards Dental Health Problems in DBCSH Dental Clinic, Ethiopia, March 2018

\begin{tabular}{|c|c|c|c|c|c|c|c|c|}
\hline \multirow[t]{2}{*}{ Variables } & \multirow[t]{2}{*}{ Options } & \multicolumn{2}{|c|}{ Case (n) } & \multicolumn{2}{|c|}{ Control (n) } & \multirow{2}{*}{$\begin{array}{c}X^{2}- \\
\text { value }\end{array}$} & \multirow[t]{2}{*}{$d f$} & \multirow[t]{2}{*}{ P-value } \\
\hline & & Frequency & Percent & Frequency & Percent & & & \\
\hline $\begin{array}{l}\text { Does oral health important for overall } \\
\text { health? }\end{array}$ & $\begin{array}{l}\text { Yes } \\
\text { No }\end{array}$ & $\begin{array}{l}121 \\
13\end{array}$ & $\begin{array}{l}90.3 \\
97.0\end{array}$ & $\begin{array}{c}129 \\
4\end{array}$ & $\begin{array}{c}96.9 \\
3.0\end{array}$ & 4.25 & I & 0.039 \\
\hline $\begin{array}{l}\text { Do you worry about your dental } \\
\text { health? }\end{array}$ & $\begin{array}{l}\text { Yes } \\
\text { No }\end{array}$ & $\begin{array}{l}123 \\
11\end{array}$ & $\begin{array}{l}91.8 \\
8.2\end{array}$ & $\begin{array}{c}128 \\
5\end{array}$ & $\begin{array}{c}96.2 \\
3.7\end{array}$ & & & \\
\hline $\begin{array}{l}\text { Why do we care about our teeth and } \\
\text { gum health? }\end{array}$ & $\begin{array}{l}\text { Have good smile } \\
\text { Prevent bad breath } \\
\text { To keep teeth healthy } \\
\text { To reduce treatment }\end{array}$ & $\begin{array}{c}24 \\
109 \\
94 \\
30\end{array}$ & $\begin{array}{l}17.9 \\
81.3 \\
70.1 \\
22.4\end{array}$ & $\begin{array}{l}53 \\
118 \\
96 \\
54\end{array}$ & $\begin{array}{l}39.8 \\
88.7 \\
72.1 \\
40.6\end{array}$ & & & \\
\hline $\begin{array}{l}\text { How much do you think dental } \\
\text { problem can affect general health? }\end{array}$ & $\begin{array}{l}\text { Always } \\
\text { Sometimes } \\
\text { Never }\end{array}$ & $\begin{array}{c}52 \\
81 \\
1\end{array}$ & $\begin{array}{c}38.8 \\
60.4 \\
0.7\end{array}$ & $\begin{array}{c}43 \\
89 \\
1\end{array}$ & $\begin{array}{l}32.2 \\
6.1 \\
0.7\end{array}$ & & & \\
\hline $\begin{array}{l}\text { How do you describe your dental } \\
\text { health? }\end{array}$ & $\begin{array}{l}\text { Excellent } \\
\text { Very good } \\
\text { Good } \\
\text { Poor }\end{array}$ & $\begin{array}{c}3 \\
4 \\
46 \\
81\end{array}$ & $\begin{array}{c}2.2 \\
2.9 \\
34.2 \\
60.4\end{array}$ & $\begin{array}{c}6 \\
54 \\
72 \\
1\end{array}$ & $\begin{array}{c}4.5 \\
40.6 \\
54.1 \\
0.7\end{array}$ & & & \\
\hline $\begin{array}{l}\text { How often did you have teeth or gum } \\
\text { problem in the last one year? }\end{array}$ & $\begin{array}{l}\text { Frequently } \\
\text { Sometimes } \\
\text { Never }\end{array}$ & $\begin{array}{c}31 \\
99 \\
5\end{array}$ & $\begin{array}{c}23.1 \\
73.9 \\
3.7\end{array}$ & $\begin{array}{c}0 \\
4 \\
128\end{array}$ & $\begin{array}{c}0 \\
3.0 \\
96.2\end{array}$ & & & \\
\hline Attitude status & $\begin{array}{l}\text { Favourable attitude } \\
\text { Unfavourable attitude }\end{array}$ & $\begin{array}{c}22 \\
112\end{array}$ & $\begin{array}{l}16.5 \\
83.5\end{array}$ & $\begin{array}{l}51 \\
82\end{array}$ & $\begin{array}{l}38.4 \\
61.6\end{array}$ & 15.87 & 1 & $<0.001$ \\
\hline
\end{tabular}

Gondar, Debre Tabor, and Addis Ababa indicated the statistical association between tooth cleaning and poor dental hygiene with dental caries. ${ }^{5,6,10}$

Moreover, individuals with gastritis had more chance of developing dental health problems. As presented in the multivariable analysis, the risk of developing dental health problems increased by threefold when individuals had gastritis. This finding is similar to a cross-sectional study conducted in Southeast Iran, they concluded that there might be a relationship between poor oral hygiene and gastric precancerous lesions. Furthermore, they concluded that gastritis infection with Helicobacter Pylori (HP) bacteria in gastric histopathology might be associated with periodontal disease. ${ }^{9}$ This can be explained in the way that an individual's oral health can have a direct impact on the gut health and vice versa. In other words, the presence of disease-causing microorganisms in the mouth can cause gums to become inflamed which can ultimately lead to gum disease. More worryingly, bad bacteria present in the saliva travels to the digestive tract when individuals swallow, causing digestive system problems including gastritis. Thus, the earlier people learn proper oral hygiene practices - such as brushing, flossing, and limiting once sugar intake - the easier it will be to avoid costly dental procedures and long-term health issues. ${ }^{9,27-29}$

\section{Strengths and Limitations of the Study}

As the study design is a case-control, cases and controls of study participants' confirmation were done by a dentist, which provides strong evidence for the measure of association. However, this study did not identify the causative agents and the pathogens involved in gastritis infection - what type of microbes were involved in gastritis infection was not investigated. Since this study was a part of the student research project, due to time and resource limitations, we did not perform kappa statistics, which quantity two measurement agreement. Other limitations can be some behavioural practices including tooth brushing 
Table 4 Tooth Brushing Practice of Study Participants DBCSH Dental Clinic, Ethiopia, March 2018

\begin{tabular}{|c|c|c|c|c|c|c|c|c|}
\hline \multirow[t]{2}{*}{ Variables } & \multirow[t]{2}{*}{ Options } & \multirow{2}{*}{$\begin{array}{c}\begin{array}{c}\text { Cases } \\
(n=134)\end{array} \\
\text { Frequency }\end{array}$} & \multicolumn{3}{|c|}{ Controls $(n=133)$} & \multirow{2}{*}{$\begin{array}{c}X^{2}- \\
\text { value }\end{array}$} & \multirow[t]{2}{*}{$d f$} & \multirow[t]{2}{*}{ P-value } \\
\hline & & & Percent & Frequency & Percent & & & \\
\hline \multirow[t]{2}{*}{ Tooth brushing practice } & Yes & 46 & 34.3 & 107 & 80.5 & 58 & I & $<0.001$ \\
\hline & No & 88 & 65.7 & 26 & 19.5 & & & \\
\hline \multirow[t]{3}{*}{ Frequency of brushing } & Daily & 28 & 60.9 & 74 & 69.2 & & & \\
\hline & Weekly & 15 & 32.6 & 33 & 30.8 & & & \\
\hline & Monthly & 02 & 4.3 & 0 & 0 & & & \\
\hline \multirow[t]{2}{*}{ Brush tooth per day } & One times & 24 & 85.7 & 57 & 77.1 & & & \\
\hline & Two times & 4 & 14.3 & 17 & 22.9 & & & \\
\hline \multirow[t]{4}{*}{ When do you brush your teeth? } & After meal & 29 & 21.6 & 67 & 50.3 & & & \\
\hline & Before meal & 6 & 4.4 & 6 & 4.5 & & & \\
\hline & In b/n meals & 3 & 2.2 & 20 & 15.0 & & & \\
\hline & Before \& after meals & 8 & 5.9 & 13 & 9.7 & & & \\
\hline \multirow[t]{3}{*}{ Reason for brushing tooth } & To avoid bad breath & 29 & 53.0 & 82 & 76.6 & & & \\
\hline & To avoid tooth decay & 40 & 87.0 & 81 & 75.7 & & & \\
\hline & To have whiter tooth & 8 & 17.4 & 71 & 66.4 & & & \\
\hline \multirow[t]{2}{*}{ Do you use tooth paste? } & Yes & 36 & 78.3 & 94 & 87.9 & 2.32 & I & 0.13 \\
\hline & No & 10 & 21.7 & 13 & 12.1 & & & \\
\hline \multirow[t]{3}{*}{ The role of tooth paste } & Kills germs & 28 & 60.9 & 94 & 87.9 & & & \\
\hline & Remove dirt & 38 & 82.6 & 89 & 83.2 & & & \\
\hline & Tastes good & 8 & 17.4 & 18 & 16.8 & & & \\
\hline \multirow{4}{*}{$\begin{array}{l}\text { Frequency of changing tooth } \\
\text { brush }\end{array}$} & Once per year & 1 & 0.7 & 3 & 2.2 & & & \\
\hline & After every 3 month & 19 & 14.2 & 41 & 30.8 & & & \\
\hline & After 6 month & 7 & 5.2 & 31 & 23.3 & & & \\
\hline & Lost or spoil & 19 & 14.2 & 32 & 24.1 & & & \\
\hline \multirow[t]{3}{*}{ What do you use for flossing? } & Match stick & 5 & 3.7 & 31 & 23.3 & & & \\
\hline & Inter dental brush & 38 & 28.4 & 67 & 50.4 & & & \\
\hline & Thread & 2 & 1.5 & 2 & 1.5 & & & \\
\hline \multirow[t]{5}{*}{ Reasons for not brushing tooth } & It hurts & 6 & 4.4 & I & 0.7 & & & \\
\hline & Causes bleeding & 44 & 32.8 & 17 & 12.7 & & & \\
\hline & No time & 13 & 9.7 & 5 & 3.7 & & & \\
\hline & No brush & 19 & 14.2 & 2 & 1.5 & & & \\
\hline & Not necessary & 7 & 5.2 & 1 & 0.7 & & & \\
\hline \multirow[t]{3}{*}{ Gum bleeding is prevented by } & Bruising the tooth & 18 & 13.4 & 42 & 31.5 & & & \\
\hline & Using vitamins & 68 & 50.7 & 106 & 79.7 & & & \\
\hline & I do not know & 60 & 44.7 & 21 & 15.8 & & & \\
\hline \multirow[t]{2}{*}{ Have you ever visited dentist? } & Yes & 95 & 70.9 & 2 & 1.5 & 138 & 1 & $<0.001$ \\
\hline & No & 39 & 29.1 & $|3|$ & 97.7 & & & \\
\hline
\end{tabular}

practices used in the analysis were self-reported by the respondents; self-reported data may introduce inaccuracy and bias into the estimates of behaviour. However, to reduce social desirability, and information bias, participants were informed to respond genuinely and honestly during oral informed consent. Moreover, due to its institution-based study, it is difficult to generalize the results to the community. Therefore, the use of this study's findings should be considered as having these inherent limitations. 
Table 5 Bivariable and Multivariable Logistic Regression Analysis of Dental Health Problems Among Adult Patients at Debre Berhan Comprehensive Specialized Hospital Dental Clinic, Ethiopia, March 2018

\begin{tabular}{|c|c|c|c|c|c|}
\hline \multirow[t]{2}{*}{ Variables } & \multicolumn{2}{|c|}{ Cross Tabulation } & \multirow[t]{2}{*}{ COR $(95 \% \mathrm{Cl})$} & \multirow[t]{2}{*}{ P-value } & \multirow[t]{2}{*}{ AOR $(95 \% \mathrm{Cl})$} \\
\hline & Cases & Controls & & & \\
\hline \multicolumn{6}{|c|}{ Age group (in years) } \\
\hline$<25$ & 33 & 42 & $0.35(0.17,0.70)$ & 0.003 & - \\
\hline $25-30$ & 28 & 36 & $0.35(0.17,0.71)$ & 0.004 & - \\
\hline $30-41$ & 28 & 35 & $0.36(0.17,0.73)$ & 0.005 & - \\
\hline$>41$ & 45 & 20 & I & & \\
\hline \multicolumn{6}{|l|}{ Sex } \\
\hline Male & 75 & 62 & I & 0.127 & - \\
\hline Female & 59 & 71 & $0.68(0.43,1.11)$ & & \\
\hline \multicolumn{6}{|l|}{ Educational status } \\
\hline No formal Edu & 53 & 22 & $3.30(1.86,5.86)$ & $<0.001$ & - \\
\hline Has formal Edu & 81 & 111 & 1 & & \\
\hline \multicolumn{6}{|l|}{ Income categories } \\
\hline$<1000$ ETB & 58 & 39 & $1.82(1.09,3.02)$ & 0.021 & - \\
\hline$\geq 1001$ ETB & 76 & 93 & I & & \\
\hline \multicolumn{6}{|c|}{ Have information about dental health? } \\
\hline Yes & 78 & 123 & $0.11(0.06,0.24)$ & $<0.001$ & $0.28(0.12,0.64)$ \\
\hline No & 56 & 10 & 1 & & \\
\hline \multicolumn{6}{|l|}{ Have radio? } \\
\hline Yes & 102 & 122 & $0.26(0.12,0.56)$ & 0.001 & - \\
\hline No & 32 & 10 & I & & \\
\hline \multicolumn{6}{|l|}{ Have television? } \\
\hline Yes & 51 & 83 & $0.37(0.23,0.61)$ & $<0.001$ & - \\
\hline No & 83 & 50 & 1 & & \\
\hline \multicolumn{6}{|l|}{ Knowledge status } \\
\hline Poor & 97 & 73 & $2.16(1.29,3.59)$ & 0.003 & - \\
\hline Good & 37 & 60 & I & & \\
\hline \multicolumn{6}{|c|}{ Do you brush your teeth? } \\
\hline Yes & 46 & 107 & $0.13(0.07,0.22)$ & $<0.001$ & $0.24(0.13,0.45)$ \\
\hline No & 88 & 26 & 1 & & \\
\hline \multicolumn{6}{|c|}{ Ever drunk alcohol? } \\
\hline Yes & 99 & 82 & $1.76(1.05,2.96)$ & 0.033 & - \\
\hline No & 35 & 51 & 1 & & \\
\hline \multicolumn{6}{|c|}{ Have diagnosed gastritis? } \\
\hline Yes & 28 & 06 & $5.59(2.23,14.01)$ & $<0.001$ & $3.12(1.14,8.57)$ \\
\hline No & 106 & 127 & I & & \\
\hline
\end{tabular}

Abbreviations: $\mathrm{COR}$, crude odds ratio; $\mathrm{Cl}$, confidence interval; $\mathrm{AOR}$, adjusted odds ratio.

\section{Conclusion}

In conclusion, the determinants of dental health problems in this study were having perceived dental health information, tooth brushing practice, and being affected by gastritis infection. Proper health information dissemination to the community about oral health-related care and dental health care practice including regular dental check-ups twice a year, proper tooth brushing practice believed to improve dental health status. However, digestive system problems like gastritis infection can increase the risk of developing dental health problems. This implies that improving community dental health care and practice through promoting proper tooth 
brushing, flossing, and preventing gastritis can enhance oral health-related quality of life among patients and the community. Moreover, since dental health is a lifelong commitment practice, comprehensive approaches should be designed based on the life-course framework to strengthen the available behavioural change communication.

\section{Abbreviations}

CVD, cardiovascular disease; DBCSH, Debre Berhan Comprehensive Specialized Hospital; DBU, Debre Berhan University; DM, diabetes mellitus; GBD, Global Burden of Disease; NCDs, non-communicable diseases; ROSC, recommended oral self-care; WHO, World Health Organization.

\section{Data Sharing Statement}

The data used to support the findings of this study are included in this manuscript (Tables 1-5).

\section{Ethical Consideration}

Ethical clearance was obtained from Debre Berhan University (DBU), College of Health Sciences (HSC), and the Ethical Review Committee (ERC) (Protocol number 10/18/SPH). Permission letter also obtained from Debre Berhan Comprehensive Specialized Hospital dental clinic to inform and support the data collection process. Oral informed consent which was approved by ERC was gained from the study participants by explaining the likely benefits of the study (Supplementary Materials). Moreover, participants were told that they can stop the interview at any point during data collection if they are uncomfortable and if they do not want to answer a particular question. Moreover, this study followed the principles of the Declaration of Helsinki and was approved by the Ethical Review Committee of DBUHSC.

\section{Acknowledgment}

We are grateful to all study participants for their willingness, devotion and commitment to participate in this study.

\section{Author Contributions}

All authors contributed to data analysis, drafting or revising the article, gave final approval of the version to be published, agreed to the submitted journal, and agree to be accountable for all aspects of the work.

\section{Funding}

There is no funding to report.

\section{Disclosure}

The authors declare that they have no conflicts of interest for this work.

\section{References}

1. FDI. The Challenge of Oral Disease. A Call for Global Action. 2nd ed. FDI World Dental Federation; 2015.

2. World Health Organization. WHO | promoting oral health in Africa; 2016. Available from: https://apps.who.int/iris/handle/10665/205886. Accessed November 11, 2021.

3. Petersen PE. [Continuous improvement of oral health in the $21 \mathrm{st}$ century: the approach of the WHO Global Oral Health Programme]. Zhonghua Kou Qiang Yi Xue Za Zhi. 2004;39 (6):441-444. Chinese.

4. Getachew D, Woldeyohannes D, Lemma S, Gelaye B. Oral health related illness and associated factors among bank workers and teachers in Addis Ababa, Ethiopia: cross-sectional study. Heal Sci J. 2017;11(6). doi:10.21767/1791-809X.1000532

5. Teshome A, Andualem G, Derese K. Dental caries and associated factors among patients attending the University of Gondar Comprehensive Hospital Dental Clinic, North West Ethiopia: a hospital-based cross-sectional study. Clin Cosmet Investig Dent. 2020;12:191-198. doi:10.2147/CCIDE.S247179

6. Tafere Y, Chanie S, Dessie T, Gedamu H. Assessment of prevalence of dental caries and the associated factors among patients attending dental clinic in Debre Tabor general hospital: a hospital-based cross-sectional study. BMC Oral Health. 2018;18(1):119. doi:10.1186/s12903-018-0581-8

7. Mulu W, Demilie T, Yimer M, Meshesha K, Abera B. Dental caries and associated factors among primary school children in Bahir Dar city: a cross-sectional study. BMC Res Notes. 2014;7(1):949. doi:10.1186/1756-0500-7-949

8. Tellez M, Zini A, Estupiñan-Day S. Social determinants and oral health: an update. Curr Oral Heal Reports. 2014;1(3):148-152. doi:10.1007/s40496-014-0019-6

9. Zahedi L, Jafari E, Torabi Parizi M, et al. The association between oral hygiene and gastric pathology in patients with dyspepsia: a cross-sectional study in Southeast Iran. Middle East J Dig Dis. 2017;9(1):33-38. doi:10.15171/mejdd.2016.49

10. Berhane HY, Worku A. Oral health of young adolescents in Addis Ababa—a community-based study. Open J Prev Med. 2014;04 (08):640-648. doi:10.4236/ojpm.2014.48073

11. Santhosh Kumar MP. Knowledge, attitude and practices towards oral health among law students in Chennai. J Pharm Sci Res. 2016;8 (7):650-653.

12. Prusty U. Oral hygiene-knowledge, attitude and practice among the health worker (ANM/ASHA) of Kamrup (Metro) District in North East Region of India. J Tradit Med Clin Naturop. 2017;06(02). doi:10.4172/2573-4555.1000215

13. Dechssa M, Cherie A. Tooth brushing practice and its determinants among adults attending dental health institutions in Addis Ababa, Ethiopia. Oral Health Dent Manag. 2017;16(2-Ap):1-8.

14. Hescot P, China E, Bourgeois D, et al. The FDI African strategy for oral health: addressing the specific needs of the continent. Int Dent $J$. 2013;63(3):113-120. doi:10.1111/idj.12044

15. Marin GH, Urdampilleta P, Zurriaga O. Determinants of dental care utilization by the adult population in Buenos Aires. Med Oral Patol Oral Cir Bucal. 2010;15(2). doi:10.4317/medoral.15.e316

16. Kassebaum NJ, Smith AGC, Bernabé E, et al. Global, regional, and national prevalence, incidence, and disability-adjusted life years for oral conditions for 195 countries, 1990-2015: a systematic analysis for the global burden of diseases, injuries, and risk factors. $J$ Dent Res. 2017;96(4):380-387. doi:10.1177/0022034517693566 
17. Augustine E, Afolabi O. Evaluation of oral health awareness of secondary school teachers. Adv Hum Biol. 2018;8(1):31. doi:10.4103/AIHB.AIHB_55_17

18. Whye Lian C, Siow Phing T, Shiun Chat C, Cheong Shin B, Hakim Baharuddin L, Bainun Jalil Che Z. Oral health knowledge, attitude and practice among secondary school students in Kuching, Sarawak. Arch Orofac Sci. 2010;5(1):9-16.

19. Kassim BA, Noor MA, Chindia ML. Oral health status among Kenyans in a rural arid setting: dental caries experience and knowledge on its causes. East Afr Med J. 2006;83(2):100-105. doi:10.4314/eamj.v83i2.9396

20. Berhan DBR. Monthly Facility Anti-Retroviral Therapy Report; 2018.

21. World Health Organisation. Oral health surveys basic methods. In: Annex 2. 5th ed. 2013:125

22. World Health Organisation. Promoting oral health in Africa: prevention and control of oral diseases and noma as part of essential noncommunicable disease interventions. World Health Organisation; 2016. Available from: https://apps.who.int/iris/handle/10665/205886. Accessed November 11, 2021.

23. Hamid HM, Abuaffan AH. Parental oral health knowledge, attitude, practice and caries status of Sudanese Cerebral Palsy children. Pediatr Heal Res. 2017;2:2. doi:10.21767/2574-2817.100015

24. Yousaf S, Ahmed MD, Asif M, Yousaf S, Munir S. A case control study to identify the risk factors of periodontitis in pregnant women in district Faisalabad. Occup Med Heal Aff. 2016;04(247):2. doi:10.4172/2329-6879.1000247
25. Ndagire B, Kutesa A, Ssenyonga R, Kiiza HM, Nakanjako D Rwenyonyi CM. Prevalence, severity and factors associated with dental caries among school adolescents in Uganda: a cross-sectional study. Braz Dent J. 2020;31(2):171-178. doi:10.1590/01036440202002841

26. Biscaglia L, Di Caccamo P, Terrenato I, Arrica MA, Seita A, Campus G. Oral health status and caries trend among 12-year old Palestine refugee students: results from the UNRWA's oral health surveys 2011 and 2016. BMC Oral Health. 2019;19(1):157. doi:10.1186/s12903-019-0844-z

27. Lin S. Why healthy digestion begins in the mouth. Verrywell Health; 2020. Available from: https:/www.verywellhealth.com/why-healthydigestion-begins-in-the-mouth-4150070. Accessed November 11, 2021.

28. Tioga Dental Orthodentics. How gastrointestinal disorders affect your teeth (and 5 Gainesville resources that can help). Tioga Dental Orthodentics; 2017. Available from: https://www.tiogadental.com/ blog/gastrointestinal-disorders/. Accessed November 11, 2021.

29. Healthline. Everything you need to know about dental and oral health. Healthline; 2019. Available from: https://www.healthline. com/health/dental-and-oral-health. Accessed November 11, 2021.
Clinical, Cosmetic and Investigational Dentistry

\section{Publish your work in this journal}

Clinical, Cosmetic and Investigational Dentistry is an international, peer-reviewed, open access, online journal focusing on the latest clinical and experimental research in dentistry with specific emphasis on cosmetic interventions. Innovative developments in dental materials, techniques and devices that improve outcomes and patient

\section{Dovepress}

satisfaction and preference will be highlighted. The manuscript management system is completely online and includes a very quick and fair peer-review system, which is all easy to use. Visit

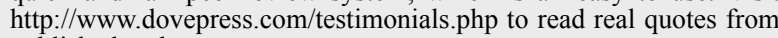
published authors. 